\title{
Urgences
}

\section{Marguerite Duras, Emily L., Paris, Minuit, 1987, 153 p.}

\section{Élisabeth Haghebaert}

Numéro 19, janvier 1988

Le tour du texte

URI : https://id.erudit.org/iderudit/025456ar

DOI : https://doi.org/10.7202/025456ar

Aller au sommaire du numéro

Éditeur(s)

Urgences

ISSN

0226-9554 (imprimé)

1927-3924 (numérique)

Découvrir la revue

Citer ce compte rendu

Haghebaert, É. (1988). Compte rendu de [Marguerite Duras, Emily L., Paris,

Minuit, 1987, 153 p.] Urgences, (19), 116-117. https://doi.org/10.7202/025456ar

Ce document est protégé par la loi sur le droit d'auteur. L’utilisation des services d'Érudit (y compris la reproduction) est assujettie à sa politique d'utilisation que vous pouvez consulter en ligne.

https://apropos.erudit.org/fr/usagers/politique-dutilisation/
Cet article est diffusé et préservé par Érudit.

Érudit est un consortium interuniversitaire sans but lucratif composé de l’Université de Montréal, l'Université Laval et l'Université du Québec à Montréal. Il a pour mission la promotion et la valorisation de la recherche. https://www.erudit.org/fr/ 


\section{Marguerite Duras: Emily L., Paris, Minuit, 1987, $153 \mathrm{p}$.}

Hommage discret à Emily Dickinson (disparue en 1886) ou à Emily Brontë, cette autre "Elle" possible, toutes soeurs "siamoises" par l'écriture, Emily L., le nouveau roman de Marguerite Duras (im)pose la question du retour du romanesque, sans pour autant exclure le parti pris autobiographique dont témoigne en parallèle $L a$ vie matérielle (1987). Anamnèse, il accommode en effet les apparences de la réalité en dédoublant l'histoire - l'enfance asiatique lointaine, apour encore parler du Siam» (p. 47), les peurs, lés pleurs, les "choses de la nuit" (p. 12). Quillebeuf et «Toup à coup, ces gens devant nous (voyageurs) ces voyageurs à nous donnés» (p. 31) - pour faire un livre impossible qui n'en finit pas de s'écrire et rend a désirable le retrait du désir ", selon l'expression de Julia Kristiva'.

Emily L. c'est «une histoire et labsence de cette histoire ${ }^{2}$, qui se fait de se défaire: "ce sont les histoires les plus terribles, celles qui ne s'avouent jamais, qui se vivent sans certitude aucune, jamais» (p. 56). Une histoire qui est simplement distraite par une autre dont le prolongement sert d'éponyme au roman. D'abord écouter cette fermme-écrivain dont le «je» mène la narration: son projet d'écrire cette histoire damour/désamour, la sienne, rêvée ou inventée: "à ce moment-là, que ce qui reste vienne de ce qu'il y a eu ou de ce quion croit qu'il y a eu, c'est équivalent..." (p. 24). Un projet sans cesse reporté par une passion qui ne peut ni ne veut s achever, malgré le déni de son interlocuteur-objet.
Écouter donc la fameuse tonalité Duras, retenue, le sobre voussoiement intime, la complicité lucide jusque dans la souffrance infligée ( «je suis toujours près de vous dans le désespoir que je vous procure» (p. 25)), face à face avec le rien qui fait dire les mots elliptiques, "pleurer les yeux» et rire aussi, beaucoup. Comme si enfin, dans «l'inintelligibilité de la vérité» (p. 89), seule comptait l'écriture, présente et absence - thème central du livre, avec l'amour, l'usure, la mort et, bien sûr, la folie -: «Ce que nous préférons, c'est écrire des livres l'un sur l'autre - et on a ri» (p. 61).

Passe alors, dans la conversation, avec les couleurs du temps et des amours encore, la seconde histoire, celle des voyageurs, étrangèrs à tout parmi le désespoir: "Si seuls au monde ils étaient, ils ne savaient plus rien de la solitude» (p. 91), lhistoire d'Emily L. ainsi nommée par le "gardien" (de ses poèmes et son secret) - "the lady" (en italique dans le texte, p. 109). L'écrivain et le lecteur regardent les personnages échoués là, dans ce bar de "l'hòtel de la Marine" de Quillebeuf, à l'embouchure de la Seine (la scène), héros naufragés d'un possible roman, très XIX" siècle et très visuel, qui se reconstitue au fil des indices et des suppositions: amours ancillaires contrariées de l'héritière du Devon (du devoir?) et du Captain d'opérette, mésalliance, déceptions, trahisons. vocation brisée et grands bateaux dans les "petites mers malaises" (p. 147). où l'on s'enivre en dansant à fuir quelque lancinant souvenir, sans parler de ce gardien follement romantique... et de ce chaste baiser à lui donné - mariage blanc infini dans la blancheur crayeuse de l'ile de Wight - par "L'amante anglaise» 1987. 
"Toutes les fernmes de mes livres, quel que soit leur àge, découlent de Lol V. Stein, c'est-à-dire d'un certain oubli deiles-mèmes" ${ }^{3}$, dit Marguerite Duras. Un oubli exigé par l'amplitude du désir qui les anime. ou la perte d'un enfant. d'un poème. Ce pourquoi chacune delles les rappelle toutes un peu: la femme du Marin de Gibraltar, Élizabeth Alione, Anne Desbaresde et, maintenant, Emily L., fermme-enfant vieillissante, déçue, déchue, au bord de la mort, "attendant la délivrance... d'on ne sait quelle insupportabilitè» (p. 54), liée à l'impossibilité d'écrire.

Par-delà l'anecdotique caution de lisibilité justifiée par la présence de l'écrivain-spectateur dans le récit, pardelà le facile charme passéiste du romanesque, équivalent du "bastringue colonial " " néoromantique de L'Amant, et pour tout cela aussi, le plaisir veritable est de retrouver - hypertextualité oblige - les constantes de l'univers durassien. "Pont-Audemer... de leau partout" (p. 28): paysages aquatiques et personnages douloureux. Normandie ou mer de Chine, lart du ressassement toujours jamais pareil rencontre la tranquille assurance du désorientement qu il procure au point de jonction entre les lieux, les êtres et les mots. Là où ils (se) manquent surtout, dans la saisie directe de l'essentiel, dans le lexique fondamental du «rien», du «rire», de la "peur", de la "mort", des «larmes», et aussi toutes les certitudes du nonsavoir dans leurs approximations maladroites. Toutes bonnes raisons d'aimer lire Emily $L$.

\section{Élișabeth Haghebaert}

I. Julia Kristeva: Soleil noir. Gallimard, Paris, 1987,265 p. (ch. VIII «La maladie de la douleur: Duras").

2. Marguerite Duras: La vie matérielle, P.O.L.. Paris, 1987, p. 32.

3. Ibid.. p. 32.

4. Ibid. p. 43.
Julia Kristeva: Soleil noir (Dépression et mélancolie), Paris, Gallimard, 1987, 269 p.

\section{Le Magazine littéraire, $\mathrm{Pa}$ - ris, no 244 (no dont le dossier est intitulé Litté- rature et mélancolie), juil- let-août 1987, $98 \mathrm{p}$.}

\section{VOUS AVEZ DIT MÉLAN- COLIE?}

Mélancolie: vague à l'âme, sensation de tristesse, d'ennui agréable/désagréable qui s'installe graduellement ou soudainement, qui me déstabilise et dans laquelle, pourtant, je suis porté à reconnaitre le plus intime sinon le meilleur de moi-même. La mélancolie, comme une errance, une dérive solitaire, endeuillée et enchantée. qui connaitrait mal son point de départ et l'objet de sa course. La mélancolie: étymologiquement, la bile noire. l'une des quatre humeurs composant le corps humain selon la longue tradition médicale aristotélo-hippocrato-galienne. Mais encore? Et vous pensez, pêlemèle, au taedium vilae d'Horace si souvent évoqué par Hubert Aquin, aux baroques, à Hamlet, à Don Quichotte décrivant l'Age d'or, à Werther, au «mal du siecle" romantique. au spleen baudelairien ("Quand le ciel bas et lourd pèse comme un couvercle/Sur l'esprit 